\title{
What Is the Acceptable Rate of Negative Appendectomy? Comment on Prospective Evaluation of the Added Value of Imaging within the Dutch National Diagnostic Appendicitis Guideline - Do We Forget Our Clinical Eye?
}

\author{
Dino Papeša Suzana Sršen Medančića Anko Antabak ${ }^{a}$ Ivica Sjekavica ${ }^{b}$ Tomislav Luetića
}

Departments of a Surgery and ${ }^{\mathrm{b}}$ Radiology, Clinical Hospital Center Zagreb, Zagreb, Croatia

We read with interest the article of Schok et al. [1]. In 2014 we did an audit of our results on pediatric appendectomy $(0-$ 18 years) in the form of a cross-sectional retrospective study that was conducted using hospital database that reviewed all appendectomies in our department in two twoyear periods (1999-2000 and 2012-2013) to see the changes after introduction of ultrasound and CT scan into practice. There were a total of 380 appendectomies performed: 154 as laparoscopic and 226 as open procedures. Regarding the pathological outcome of the operation, negative appendectomy rate (NAR) was $12 \%$ (47 patients) and perforation rate (PR) was $18 \%$ (69 patients). In children younger than 5 years of age (26 patients) PR was $30 \%$ and NAR $8 \%$. Regarding imaging, 83 patients (22\%) received preoperative ultrasound examination, and 2 received a CT scan $(0.5 \%)$. The NAR and PR among children who received preoperative imaging were $8.4 \%$ (7/ 83 ) and $15.7 \%$ (13/83), respectively, which did not differ significantly $(\mathrm{p}>0.05)$ from children who did not receive any imaging.

To evaluate our results we searched Pubmed and found that NAR and PR in our series were comparable to other similar reports, including the report from Schok et al. As mentioned by the authors, accord- ing to Dutch guidelines, such rates may be considered unacceptable. So what is the acceptable NAR? When searching through the literature, one may find reports with considerably low NAR, that is, below $10 \%$. However, there are several factors that apparently decrease NAR.

The three largest series on pediatric appendectomy within the last two years are by Bachur that included 55,227 appendectomies (NAR 3.6\%), Oyetunji that included 250,783 appendectomies (NAR 6.7\%), and Cheong that included 78,625 children from US and 41,492 children from Canada (NAR 6.3 and $4.3 \%$ ) [2-4]. Large database analyses report only the discharge letter diagnosis or intraoperative appearance of the appendix without analyzing the histology report. This is present in all three previously mentioned reports. Had we used this criterion, the rate of negative appendectomy in our series would be $3 \%$ since of 47 negative appendectomies, 32 (68\%) were initially during operation diagnosed as inflamed appendicitis and were later on histological examination found to be non-inflamed. Further, even if histology reports are used, the histological definition of appendicitis also differs. Histological definition of inflamed appendix is not described in many reports that have low negative appendec- tomy rates [5], and one study has clearly shown that the change in histological criteria for diagnosing inflamed appendix raised the negative appendectomy by $3-6 \%$ [6]. Finally, as noted in previous reports, published figures are often without adjustment for age and sex as many hospitals admit proportionally fewer teenage girls or young infants, which are two high-risk groups [7].

For example, one large analysis of 30 pediatric hospitals in the United States found the reported NAR ranging from 0 to $17 \%$, and PR ranging from 20 to $76 \%$. Such differences are most likely the consequence of the aforementioned factors [8].

Regarding the usage of imaging in Europe, this method traditionally plays a modest role in the evaluation of suspected appendicitis when compared to the ultrasound (US) [7]. Although in some studies preoperative US and CT scan did lower the rates of negative appendectomy, both our results and those of Schok et al. led to the conclusion that diagnosis of appendicitis should still mainly be based on history, clinical and laboratory data. Only the development of fast, inexpensive, accurate and non-ionizing radiation imaging modality will influence negative appendectomy rates in a significant way.
KARGER 125

(c) 2015 S. Karger AG, Base

0253-4886/15/0323-0181\$39.50/0
Dino Papeš, MD

Department of Surgery

Clinical Hospital Center Zagreb

Šalata 2, HR-10000 Zagreb (Croatia)

www.karger.com/dsu 


\section{References}

1 Schok T, Simons PC, Janssen-Heijnen ML, Peters NA, Konsten JL: Prospective evaluation of the added value of imaging within the Dutch national diagnostic appendicitis guideline - do we forget our clinical eye? Dig Surg 2014;31:436-443.

2 Oyetunji TA, Ong'uti SK, Bolorunduro OB, Cornwell EE 3rd, Nwomeh BC: Pediatric negative appendectomy rate: trend, predictors, and differentials. J Surg Res 2012;173:16-20.

$>3$ Bachur RG, Hennelly K, Callahan MJ, Chen C, Monuteaux MC: Diagnostic imaging and negative appendectomy rates in children: ef- fects of age and gender. Pediatrics 2012;129: 877-884.

4 Cheong LH, Emil S: Outcomes of pediatric appendicitis: an international comparison of the United States and Canada. JAMA Surg 2014;149:50-55.

5 Saito JM, Yan Y, Evashwick TW, Warner BW, Tarr PI: Use and accuracy of diagnostic imaging by hospital type in pediatric appendicitis. Pediatrics 2013; 131:e37-e44.

-6 Mariadason JG, Wang WN, Wallack MK, Belmonte A, Matari H: Negative appendicectomy rate as a quality metric in the management of appendicitis: impact of computed tomography, Alvarado score and the definition of negative appendicectomy. Ann R Coll Surg Engl 2012;94:395-401.

7 Lander A: The role of imaging in children with suspected appendicitis: the UK perspective. Pediatr Radiol 2007;37:5-9.

8 Newman K, Ponsky T, Kittle K, Dyk L, Throop C, Gieseker K, Sills M, Gilbert J: Appendicitis 2000: variability in practice, outcomes, and resource utilization at thirty pediatric hospitals. J Pediatr Surg 2003;38: 372-379; discussion 372-379. 